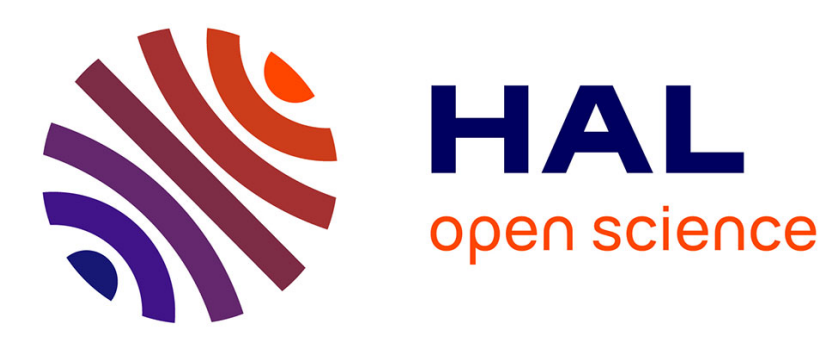

\title{
Correlation between D.C. bulk conductivity and impurities in undoped poly (p-phenylene)
}

\author{
F. Maurice, G. Froyer, M. Minier, M. Gauneau
}

\section{To cite this version:}

F. Maurice, G. Froyer, M. Minier, M. Gauneau. Correlation between D.C. bulk conductivity and impurities in undoped poly (p-phenylene). Journal de Physique Lettres, 1981, 42 (18), pp.425-427. 10.1051/jphyslet:019810042018042500 . jpa-00231964

\section{HAL Id: jpa-00231964 https://hal.science/jpa-00231964}

Submitted on 1 Jan 1981

HAL is a multi-disciplinary open access archive for the deposit and dissemination of scientific research documents, whether they are published or not. The documents may come from teaching and research institutions in France or abroad, or from public or private research centers.
L'archive ouverte pluridisciplinaire HAL, est destinée au dépôt et à la diffusion de documents scientifiques de niveau recherche, publiés ou non, émanant des établissements d'enseignement et de recherche français ou étrangers, des laboratoires publics ou privés. 


\title{
Correlation between D.C. bulk conductivity and impurities in undoped poly (p-phenylene)
}

\author{
F. Maurice, G. Froyer, M. Minier and M. Gauneau \\ Centre National d'Etudes des Télécommunications, Centre Lannion B, Route de Trégastel, B.P. 40, 22301 Lannion, France
}

(Reçu le 5 janvier 1981, révisé le 18 juin, accepté le 28 juillet 1981)

\begin{abstract}
Résumé. - La conductivité continue du poly(p-phénylène) non dopé préparé selon la méthode de Kovacic suit approximativement une loi d'Arrhenius au-dessus de l'ambiante. Nous avons corrélé la chute de conductivité lors des étapes de lavage et de recuit au départ de cuivre, et mesuré sur le produit le plus pur une faible conductivité de $10^{-17}(\Omega . \mathrm{cm})^{-1}$ à $80^{\circ} \mathrm{C}$, associée à une énergie d'activation de $1,1 \mathrm{eV}$.
\end{abstract}

\begin{abstract}
The D.C. conductivity of non doped poly(p-phenylene) prepared by Kovacic's method fits an Arrhenius law above room temperature. We have correlated the drop of the conductivity during the steps of washing and annealing with the elimination of copper in the material, and we have measured on the purer poly(p-phenylene) a low conductivity of $10^{-17}(\Omega . \mathrm{cm})^{-1}$ at $80^{\circ} \mathrm{C}$ associated with an activation energy of $1.1 \mathrm{eV}$.
\end{abstract}

1. Introduction. - Conjugated polymers have recently gained considerable interest since the observation that they can form highly conductive charge transfer complexes with donor or acceptor molecules.

Polyacetylene, $(\mathrm{CH})_{x}$, has been the subject of most studies [1] [2] because it is one of the simplest molecules, and because its large specific area makes it very attractive for electro-chemical applications.

Poly(p-phenylene), P.P.P., is another simple conjugated molecule which is stable in air, but cannot yet be obtained in film form.

The possibility of doping P.P.P. to the metallic state has been demonstrated by Baughman et al. [3] : conductivities up to $500(\Omega . \mathrm{cm})^{-1}$ have been reached with the acceptor $\mathrm{AsF}_{5}$.

We have focused our attention on the characterization of undoped P.P.P. prepared by the method described by Kovacic et al. [4], and we report data simultaneously on the chemical composition and on the D.C. conductivity of poly(p-phenylene) pellets.

Previously reported values for the room temperature D.C. conductivity of the undoped polymer were in the range $10^{-11}-10^{-12}(\Omega . \mathrm{cm})^{-1}$ [3] with an activation energy of $0.7 \mathrm{eV}$, but we observed that improving the purity of the samples by washing or annealing them resulted in a dramatic decrease of the conductivity down to $10^{-17}(\Omega . \mathrm{cm})^{-1}$ at $80^{\circ} \mathrm{C}$, and in a slight increase of the activation energy up to $1.1 \mathrm{eV}$.
2. Experimental methods. - We performed two synthesis of poly(p-phenylene) by the oxidative cationic polymerization of benzene [4], which involves the use of $\mathrm{CuCl}_{2}$ and $\mathrm{AlCl}_{3}$, and which gives a brown powder with non negligible contents of $\mathrm{Al}, \mathrm{Cl}$ and $\mathrm{Cu}$.

We used two complementary means of purification : washing the powder in boiling $\mathrm{HCl}$, then in $\mathrm{NaOH}$, and annealing pellets made of the compressed powder $\left(820 \times 10^{6} \mathrm{~Pa}\right.$ in a $1.3 \mathrm{~cm}$ diameter $\mathrm{KBr}$ die) for $24 \mathrm{~h}$ in an oven at $400{ }^{\circ} \mathrm{C}$ under dry nitrogen flow. Besides improving purity, annealing is also known to improve crystallinity [5] [7].

There were four steps of purification for each synthesis, and the chemical analysis were performed at each step on pellets by C.N.R.S. (Fig. 1a) (O by coulometry, $\mathrm{Cl}$ by potentiometry, $\mathrm{Cu}, \mathrm{Al}$ by atomic absorption spectroscopy or plasma emission) and by C.N.E.T. (Fig. 1 b) $(\mathrm{Cl}, \mathrm{Al}, \mathrm{Cu}, \mathrm{Fe}$ by spark source mass spectrometry).

The high D.C. resistivity of the pellets was measured from $400^{\circ} \mathrm{C}$ to room temperature in an atmosphere of Argon. $1 \mathrm{~cm}$ diameter contacts were made on both faces of the pellet under test with either silver or gold point, electrodag, or evaporated aluminum or gold, and we recorded the transverse current corresponding to an imposed electric field of Ca. $1200 \mathrm{~V} / \mathrm{cm}$. We verified that there was no spurious effect like : contact effect, non ohmicity, surface currents (an additional 


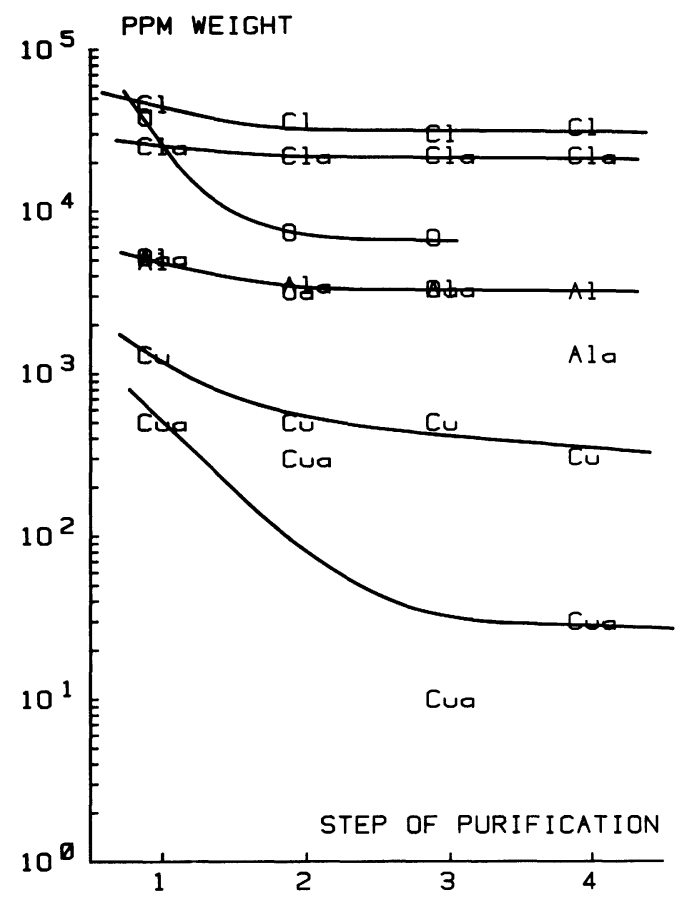

a)

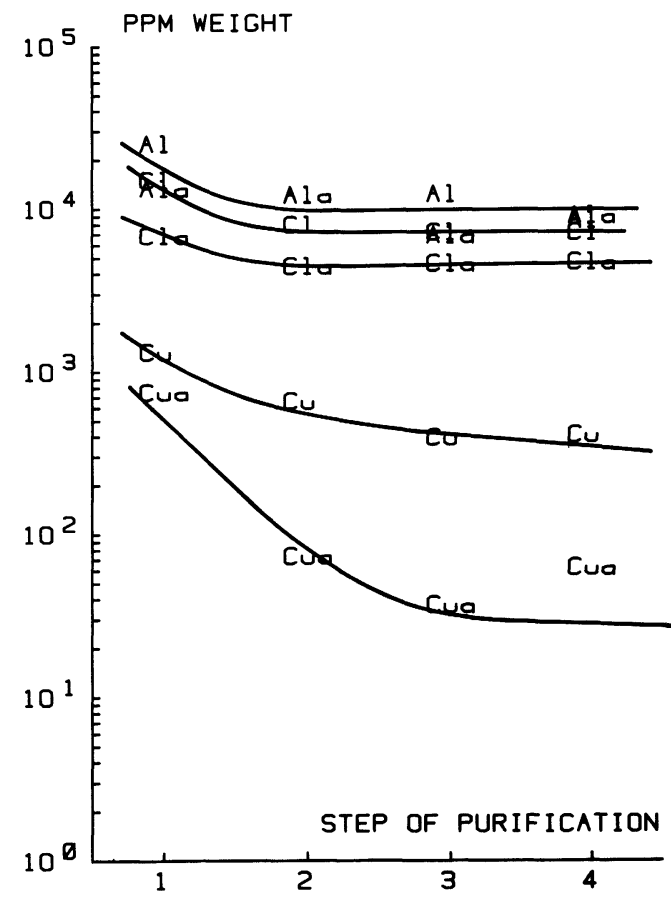

b)

Fig. 1. - Effect of washing and annealing on the impurity contents in pellets of P.P.P. produced by synthesis B. Subscript a refers to annealed samples. $1 a$ : data from C.N.R.S.; $1 b$ : data from S.S.M.S.

guard ring did not change the recorded currents above $10^{-13} \mathrm{~A}$ ), and no dependence on the compaction procedure [6], and so we could simply calculate the bulk conductivity of the compressed material.

3. Results. - The conductivity measurements were reproducible and the currents always reached steady values as rapidly as allowed by the $\mathrm{RC}$ time constant of the electrical circuit ; that supports the old idea of electronic transport in the material [6].

The Arrhenius plots of the D.C. conductivity are given in figures $2 a$ (synthesis A) and $2 b$ (synthesis B)

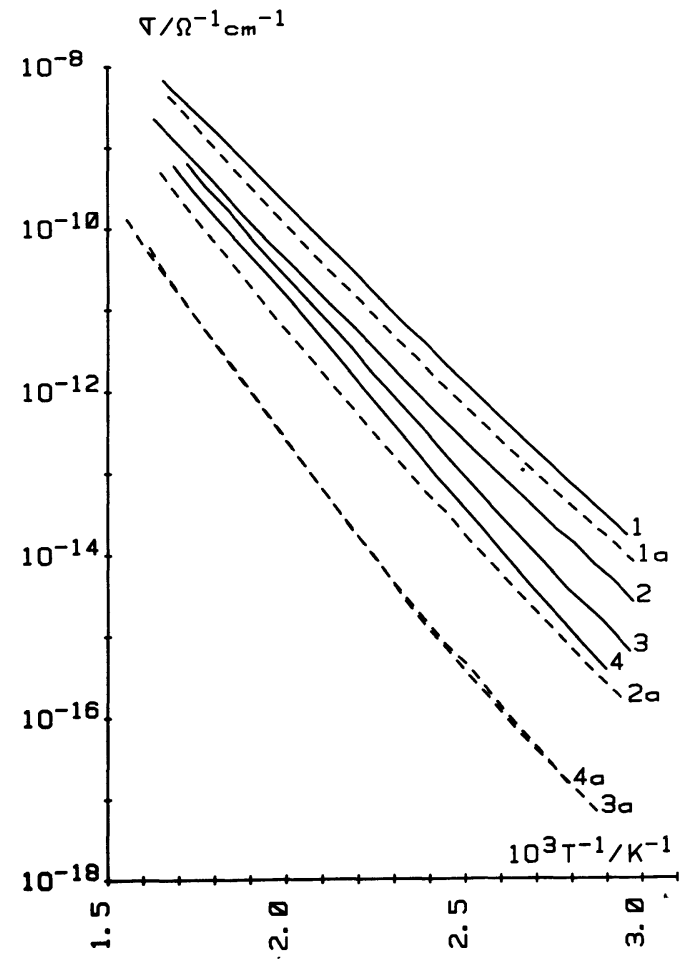

a)

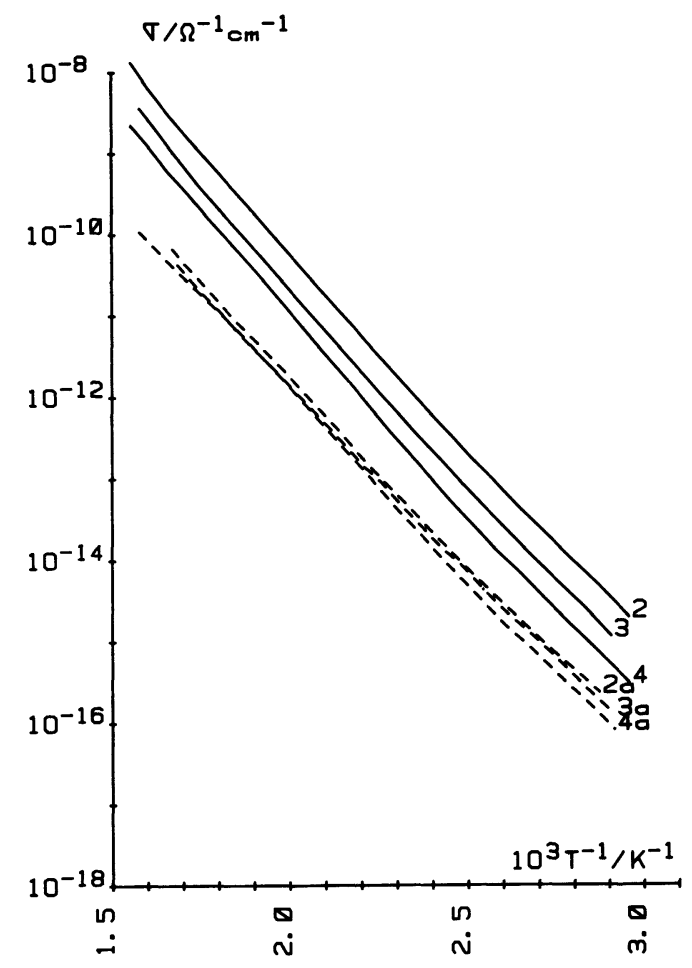

b)

Fig. 2. - D.C. conductivity of undoped poly(p-phenylene) pellets versus reciprocal temperature. Dotted lines with subscript a are for annealed samples. Numbers refer to the successive steps of purification as in figure $1.2 a$ : synthesis $\mathrm{A} ; 2 b$ : synthesis $\mathrm{B}$. 
and they differ from straight lines only by a slight upward curvature.

The effect of the successive washings in $\mathrm{HCl}$ and $\mathrm{NaOH}$ (solid lines) is clearly to lower the conductivity by a factor of $\mathrm{Ca} .3$ at each step.

Annealing results as well in a dramatic decrease of conductivity when the starting material is sufficiently pure, and there seems to exist a lower limit which might characterize the synthesis : the lowest measured conductivities are at $80^{\circ} \mathrm{C}: 10^{-17}(\Omega . \mathrm{cm})^{-1}$ for synthesis $A$, and $2 \times 10^{-16}(\Omega . \mathrm{cm})^{-1}$ for synthesis $B$.

The activation energy for P.P.P. B is nearly constant, around $1 \mathrm{eV}$. For P.P.P. A it increases slightly as purification proceeds from 0.85 to $1.1 \mathrm{eV}$.

Figures $1 a$ and $1 b$, which concern P.P.P. B, show the effect of washing and annealing on the major impurity contents. The results of S.S.M.S. (Fig. 1b) give the same trends as the analytical methods used by C.N.R.S. (Fig. 1a), though the absolute values are differing, except for $\mathrm{Cu}$ which was used for calibration of SSMS

We noted no change in $\mathrm{Al}$ contents beyond step 2, neither by washing or annealing; in a same way there is no visible effect of washing on Chlorine and Oxygen beyond step 2 , but their contents are divided respectively by 1.5 and 2 after annealing.

On the contrary washing acts to eliminate copper, as subsequent annealing does, and the effect of annealing is more and more dramatic after each new sequence of washings, making the $\mathrm{Cu}$ content fall at the end in the range 10-100 p.p.m., characteristic of the minor impurity contents (iron for example).

The minimum values of the impurity contents in a well purified, annealed pellet of P.P.P. B are : $\mathrm{Cl}=2.2 \%, \mathrm{O}=\mathrm{Al}=0.35 \%, \mathrm{Cu}<100$ p.p.m.

Partial analysis data for P.P.P. A support the same evolution and the final values are $\mathrm{Cl}=1.1 \%$, $\mathrm{O}<0.5 \%, \mathrm{Al}=0.4 \%, \mathrm{Cu}<100$ p.p.m.
The difference between both materials is then the chlorine content which is more important in the second. In both cases of P.P.P. A and B the $\frac{C}{\mathrm{H}+\mathrm{Cl}}$ ratio was 1.5 or a little more and might support the idea of some crosslinking.

4. Discussion. - As the washings are not expected to change the crystallinity or the degree of crosslinking in P.P.P., the observed decrease of conductivity after a series of washings must be correlated with the loss of copper, the only impurity whose content is lowered by washing (beyond the second step).

The case of annealing is more complicated since there is an increase in crystallinity [5] [7], in crosslinking [8], and simultaneously losses of chlorine, oxygen, and copper. But we noted that the effect of annealing on lowering the conductivity is first small (step 1 in Fig. 2a), then increases in steps 2 and 3, and finally saturates in step 4 ; and that can only be correlated with the losses of copper, which obey the same laws (Fig. 1), since neither the crystallinity enhancement, nor the crosslinking process were ever reported to be so much dependent on the step of purification.

So, copper seems to play a role in enhancing the conductivity of non doped poly(p-phenylene).

We are not sure whether it is acting as dopant of the conjugated portions of the polymer chains, or if it helps in the interchain transport. The nearly constant value of the activation energy of the conductivity, reaching $1.1 \mathrm{eV}$ for the purer P.P.P. A favours the latter hypothesis, and the deduced energy gap of at least $2.2 \mathrm{eV}$, assuming an intrinsic semiconductor band structure, approaches the experimental optical absorption edge of the powder, which we observed near $2.8 \mathrm{eV}$.

\section{References}

[1] The physics and chemistry of low dimensional solids, REIDEL, D. Pub. Co., 1980, Nato ASI series.

[2] Ito, T., Shirakawa, H., Ikeda, S., J. Polym. Sci. Polym. Chem. ed. 12 (1974) 11.

[3] Shacklette, L. W., Chance, R. R., Ivory, D. M., Miller, G. G., Baughman, R. H., Synth. Metals 1 (1979) 307.

[4] Kovacic, P., Kyriakis, A., J. Am. Chem. Soc. 85 (1963) 454.
[5] Kovacic, P., Feldman, M. B., Kovacic, J. P., Lando, J. B., J. Appl. Polym. Sci. 12 (1968) 1735.

[6] Eley, D. D., Pacini, B. M., Polymer 9 (1968) 159.

[7] Froyer, G., Maurice, F., Mercier, J. P., Rivière, D., Le Cun, M., Auvray, P., Accepted for publication in Polymer. [8] LeRner, N. R., J. of Polymer science (polymer chemistry edition) Vol. 12 (1974) 2477-2495. 